\title{
A MÚSICA GOSPEL E OS USOS DA “ARMA DA CULTURA". REFLEXÕES SOBRE AS IMPLICAÇÕES DE UMA EMENDA.
}

\author{
Raquel Sant'Ana ${ }^{1}$
}

RESUMO: Este trabalho trata do caso do reconhecimento da música gospel como manifestação cultural a partir de emenda à Lei no 8.313/91 (a "Lei Rouanet") de Incentivo à Cultura. Embora a lei Rouanet já reconhecesse a "música" como campo geral apto a receber incentivos e alguns projetos gospel já houvessem sido contemplados, a emenda provocou críticas e mesmo um parecer contrário por parte do Ministério da Cultura. A análise deste caloroso debate permite problematizar os diferentes sentidos com que têm sido acionados termos como 'Cultura', 'Estado' e 'Religião'. Essa reflexão se combina ao trabalho de autores como Talal Asad e Susan Wright, que têm demonstrado que tais categorias precisam ser compreendidas como historicamente construídas e como 'nativas', capazes de legitimar e deslegitimar certas configurações de poder. Assim, a reflexão sobre os usos da "arma da cultura" pelos evangélicos no Brasil (problema para o qual Clara Mafra chamava a atenção em 2011) revela confluências desafiadoras entre a religião e o estabelecimento de políticas públicas.

PALAVRAS-CHAVE: Política Cultural - Música gospel - Evangélicos - Política - Estado

Recebido em:Agosto, 2013

Aceito em: Novembro, 2013

Para citar este artigo:

SANT"ANA, Raquel; "A música gospel e os usos da "arma da cultura". "Reflexões sobre as implicações de uma emenda." In: Revista Intratextos, 2013, vol 5, no1, p. 23-41. DOI: http://dx.doi.org/10.12957/intratextos.2013.7097

\footnotetext{
${ }^{1}$ Doutoranda no Programa de Pós-Graduação em Antropologia Social da Universidade Federal do Rio de Janeiro/ Museu Nacional e pesquisadora do Núcleo de Estudos da Cultura no Capitalismo Tardio da Universidade Federal Fluminense. Email: emailderaquel@gmail.com.
} 


\section{1-Três linhas}

A música gospel faz parte da música popular brasileira ${ }^{2}$

José Sarney

Embora tenha tido uma repercussão pública ampla, a Lei n¹2.590/2012 se resume às três breves linhas que cito abaixo:

\footnotetext{
Para os efeitos desta Lei, ficam reconhecidos como manifestação cultural a música gospel e os eventos a ela relacionados, exceto aqueles promovidos por igrejas
}

Inicialmente proposta pelo Deputado Federal Costa Ferreira ${ }^{3}$ como uma lei à parte, ela foi reformulada e aprovada em versão definitiva no ano de 2007, pelo Bispo Robson Rodovalho, fundador da Comunidade Evangélica Sara Nossa Terra e então deputado pelo PFL/DF ${ }^{4}$. Com essa mudança, que contou com a redação do acessor da Frente Parlamentar Católica, o advogado Paulo Fernando Melo, o projeto passou a ser de emenda à Lei $\mathrm{n}^{\circ} 8.313$ de 23 de dezembro de 1991, popularmente conhecida como "Lei Rouanet".

Embora não trate apenas da renúncia fiscal e ratifique e dê corpo a outras formas de incentivo como o estabelecimento do FNC (Fundo Nacional de Cultura), a Lei Rouanet é mais conhecida como uma lei de patrocínio.

Há, aliás, um amplo debate repleto de críticas à centralidade da Lei Rouanet no incentivo à cultura, já que a lógica do patrocínio daria um caráter de gestão privada à política cultural, característica de muitas outras mudanças nas políticas públicas nos anos 1990, no Brasil, que teriam inspiração em um receituário neoliberal (RUBIM, 2007).

Embora, para autores como Rubim (2007), Sarkovas (2005) e Olivieri (2004) a Lei Rouanet seja legado desse período de ausência de uma atuação efetiva do Estado nas políticas culturais, podemos perceber no vocabulário da Lei e nos objetivos estabelecidos em seu artigo primeiro a absorção e o diálogo com os recentes esforços pela organização de uma área simultaneamente de estudos e ação política sob o título de "Políticas Culturais".

\footnotetext{
${ }^{2}$ Declaração dada à Agência Senado em 16 de setembro de 2011.

${ }^{3}$ Partido Social Cristão do estado do Maranhão.

${ }^{4}$ Partido da Frente Liberal (que hoje se chama Democratas) do Distrito Federal.
} 
Há, como demonstra Susan Wright (1999), um movimento internacional de absorção de parte das demandas e das diversas formas assumidas pelos vocabulários da 'cultura' na formulação de políticas públicas que, no caso da UNESCO (Organização das Nações Unidas para a educação, a ciência e a cultura), significou uma associação com representantes da academia e seus saberes autorizados acerca deste conceito. $\mathrm{O}$ trabalho de pesquisadores que participaram desse processo, como Néstor García Canclini (1987) é, simultaneamente, um programa de estudos e de ação.

Com enorme influência e participação na construção da área de políticas culturais na América Latina, a ênfase desses autores é na importância da valorização e do intercâmbio de culturas populares e locais com a produção erudita e midiática (GARCÍA CANCLINI, 1987; MILLER E YÚDICE, 2002).

É também esse o tom da estruturação das políticas culturais brasileiras nas últimas décadas, o qual já estava presente na Lei Rouanet: valorização de uma diversidade cultural que dê espaço a especificidades locais e de minorias (RUBIM, 2007). Os limites do que se entende por 'cultura', porém, não são tão claros na lei como na obra desses intelectuais.

Alguns termos encontram definição no próprio texto da lei, como é o caso de "patrocínio", delimitado no Artigo 23, II. Mas “cultura", ou "atividade cultural” não contam com esse mesmo esforço (ou possibilidade) de precisão. $\mathrm{O}$ objeto de pertinência da lei é exemplificado em artigos que tratam de temas prioritariamente de arte e deixam o campo "outros" como brecha para casos imprevistos.

São apontados, porém, os horizontes do tipo de iniciativa que se pretende financiar. O Artigo 25 afirma que os projetos de "natureza cultural” deverão

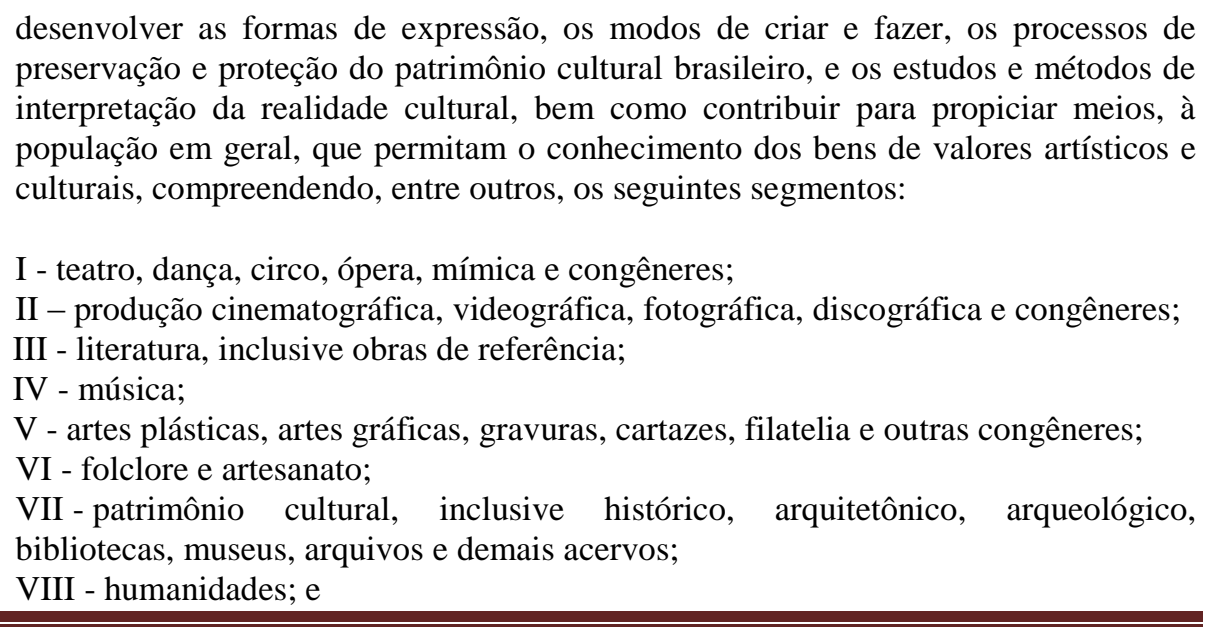


IX - rádio e televisão, educativas e culturais, de caráter não-comercial.

Sendo assim a música (em geral) já estava inserida na Lei desde a sua primeira formulação. Com base nesse texto, já haviam sido contemplados projetos relativos à música gospel (como, por exemplo, uma turnê da cantora Aline Barros), antes da Lei proposta pelo Bispo Rodovalho ser aprovada.

É preciso dizer, ainda, que não há nenhuma outra especificação de gênero musical além da emenda do gospel, que foi acrescentada de maneira um pouco isolada no Capítulo V, "Disposições Gerais", onde se encontra entre a institucionalização de Conselhos de Cultura nos municípios e a criação da Comissão Nacional de Incentivo à Cultura.

Se a emenda é redundante, a que se deve a pressão e o trabalho para a aprovação da emenda, que, aliás, foi votada em regime de urgência? Por que ela recebe oposição e pedidos de cautela por parte do MinC (Ministério da Cultura)? Que repercussões pode ter essa redundância legal?

A justificativa para a reafirmação, segundo os proponentes, se dá pela dificuldade que os projetos relacionados ao gospel encontrariam nas avaliações no Ministério da Cultura. Arolde de Oliveira, dono da MK Publicitá, uma das maiores empresas do mercado gospel e ex-parlamentar, declarou que haveria uma "insubordinação" por parte do MinC, e o número de projetos contemplados seria desproporcionalmente pequeno para o tamanho e a lucratividade do gospel, que movimentaria bilhões de reais anuais, e seria uma das grande apostas do setor fonográfico brasileiro em tempos de reestruturação ${ }^{5}$.

Já no texto original do projeto, o trecho que aborda a "justificação" conta com quatro parágrafos que seguem diferentes linhas de argumentação. No primeiro deles, é atribuída uma origem ancestral ao gospel que o associa à história da escravidão (ainda que, nesse caso, estadunidense) e, consequentemente, ao imaginário de lutas pela liberdade construído em torno dessa história:

\begin{abstract}
A música gospel é um gênero musical de origem afro-americana, nascido nas fazendas de escravos no sul dos Estados Unidos. Em sua forma original era geralmente interpretada por um solista, acompanhada de um coro e um pequeno conjunto instrumental. Atualmente nos Estados Unidos e em outros países, o Gospel está incluído como uma categoria tradicional de música cristã.
\end{abstract}

\footnotetext{
${ }^{5}$ Segundo a avaliação da Associação Brasileira de Produtores de Discos esse é um mercado em que a venda de cópias ilegais tem um impacto menor por questões morais, permitindo avanços na venda de discos originais, em queda em outros nichos de mercado.
} 
Além disso, o gospel é relacionado a uma tradição internacional consolidada e a uma forma sonora específica. O parágrafo seguinte estabelece o que seria o gospel brasileiro:

\begin{abstract}
A música cristã no Brasil se chama gospel. E originou um novo tipo de festa chamada balada gospel, onde são proibidas as bebidas alcoólicas, drogas e até mesmo cigarros. O objetivo principal é a evangelização, ou seja, que as pessoas confraternizem e conheçam a palavra de Deus. Os eventos se espalham pelo País, com um número cada vez maior de adeptos que reúnem o prazer de uma bela música, com as informações e conhecimentos religiosos. O cenário gospel está diversificado com a formação de bandas de evangelismo a bandas de louvor e adoração, com os mais variados ritmos desde rock até baião.
\end{abstract}

A maneira como o gospel é descrito remete a uma noção de 'subcultura' (Bennett, 1999), já que, no Brasil, esse rótulo não estaria associado à especificidade sonora que possui no cenário estadunidense. A citada "balada gospel" (termo estranho aos principais relatos sobre essa música e que parece ter sido inserido nesse projeto para dar unidade a uma série de iniciativas dispersas) reuniria práticas específicas em resultado do compartilhamento de certas visões de mundo e de um estilo de vida.

A diversificação sonora é apresentada em conjunto com sua expansão em termos de adeptos (o que lhe dá mais representatividade) e com uma consolidação de mercado que se segue nos dois parágrafos seguintes:

\footnotetext{
Destacamos alguns eventos de música gospel já realizados como o SOS Vida, Canta Rio e Gospel Night. Todos em território nacional, com a vibração e a participação de milhares de jovens que buscam a alegria de viver com segurança, a diversão sem apelação e a religiosidade integrada ao cotidiano.

Com o crescimento da música gospel no Brasil, em 2004 foi criada a categoria de Melhor Álbum Cristão em Música Portuguesa, no concurso Grammy Latino 2007.Concorrem vários grupos musicais e duas gravadoras evangélicas, ambas do Rio de Janeiro. Intensificam-se, pois os trabalhos musicais deste gênero.
}

Os termos do mercado e de uma "religiosidade integrada ao cotidiano" tentam demonstrar, portanto, que o gospel teria independência em relação às instituições eclesiásticas. Ele configuraria uma religiosidade dispersa e um mercado consolidado. A esfera da economia universaliza o que a religião parece ter de específico, além de remeter a uma importância para a própria economia do país.

Da mesma forma, ao restringir a aplicação da Lei a eventos que não sejam organizados por igrejas, a própria emenda delimita um nicho de mercado e expressão. Uma cultura. A emenda, ao mesmo tempo que visa a "elevar" o gospel "ao nível das demais manifestações culturais", o faz enfatizando sua singularidade. 
Essa ênfase é retomada com algum vigor no relatório da Comissão de Educação, Cultura e Esporte, que enfatiza que o gospel "Integrou-se à dinâmica cultural brasileira, perpassando os diversos segmentos da sociedade e integrando-se às culturas regionais que compõem a diversidade do nosso País." A falta de especificidade sonora se torna um elemento positivo, pois abarcaria as "localidades" tão caras ao modelo de cultura que, como vimos, vem se afirmando nas últimas décadas e já pode ser percebido na Lei Rouanet. O gospel tem a especificidade de um modo de fruir, de uma "vibração", mas abarca as diversidades regionais.

Nesse rápido olhar para os textos oficiais encontramos, portanto, elementos que ressaltam a especificidade do gospel por sua relação com espaços que não são institucionalmente ligados à Igreja. Há uma ênfase em aspectos que vinculam essa música a fatores valorizados na concepção de política cultural que permeia a Lei Rouanet.

No entanto, se para Magno Malta a emenda acabou com a "área cinza entre doutrinação e arte" ${ }^{6}$, um breve passeio pela repercussão da emenda demonstra que a área cinza é bem maior.

\section{2-A "área cinza"}

Poucas vezes os evangélicos brasileiros ousaram utilizar a 'cultura como arma' a seu favor e, quando o fizeram, demonstraram uma grande falta de familiaridade com o instrumento ${ }^{7}$

Clara Mafra

No dia 10 de janeiro de 2011, quando os jornais ainda fervilhavam com a ressaca do ano novo e as expectativas para um novo mandato presidencial, uma notícia foi anunciada em tons que iam do alarmismo à emocionada comemoração. Não era manchete, mas ocupou por uns dias o espaço das notas irônicas dos segundos cadernos. Era a notícia de que o gospel ${ }^{8}$ havia sido reconhecido como manifestação cultural e teria oficialmente direito a batalhar os recursos da Lei Rouanet.

\footnotetext{
${ }^{6}$ Declaração à Folha de São Paulo em 10/01/2012.

7 MAFRA, Clara. A"arma da cultura" e os "universalismos parciais". Mana, Rio de Janeiro, v. 17, n. 3, Dec. 2011 . Pp. 608,609.

${ }^{8}$ No Brasil, a indústria fonográfica chama de gospel as músicas de conteúdo cristão (católicas ou evangélicas), independentemente da sua sonoridade.
} 
A grande contradição que confere ironia ou preocupação a esses textos, e aparece mesmo nas declarações dadas pelo MinC, é entre o par "religião" e "dinheiro público". Essa justaposição, por si só, já confere incômodo e serve de eixo para o desdobramento de outras linhas de contradições.

A matéria de 10 de janeiro de 2012, do jornal "O Globo", por exemplo, enfatiza a conexão entre interesses pessoais dos parlamentares que teriam trabalhado para a aprovação da emenda, ao incluí-los entre os beneficiados com a emenda e parte dos que "fazem shows gospel" ao lado de cantores e religiosos:

Agora, padres, pastores, cantores e parlamentares que se apresentam e fazem shows
gospel poderão recorrer aos benefícios da Lei Rouanet.(...) são exatamente
deputados e senadores evangélicos, que participam de cultos e que também são
pastores, que mais comemoram a decisão da presidente.

A conclusão da matéria também é em tom de crítica, lembrando que o Ministério da Cultura teria recomendado cautela quanto ao projeto, por receio de uma "exploração religiosa dessa decisão".

Essa preocupação do MinC já havia sido relatada por esse mesmo jornalista, quando noticiou no mesmo jornal, em 28 de dezembro de 2011, que o senado havia aprovado o projeto. Nessa ocasião, o jornalista consultou Bebeto Alves, responsável pelo setor de música da FUNARTE e que teria aconselhado a Casa Civil a ter cautela.

É um assunto polêmico, um tema delicado e que precisa de um pouco de cuidado. A música gospel é, sim, uma manifestação cultural num país onde os gêneros musicais são muito amplos e variados. Mas tem uma questão de fundo, que é a catequese, a dinâmica religiosa e litúrgica. O risco é de haver uma distorção do entendimento de expressão e linguagem de cultura com evento de cunho religioso. Imagino que deva ter algum impedimento quanto a isso. De se coibir distorções no uso das benesses da lei.

A música gospel poderia ser tida como cultura por ser música, mas seu caráter de experiência religiosa seria um impedimento a isso e uma "distorção da linguagem da cultura", que aqui não comporta a religião para receber "benesses da lei”. A diversidade valorizada nos gêneros musicais "amplos e variados" é contraposta à força da palavra "catequese", que remete a uma tentativa de combate ao diferente e à imposição de uma religião.

A cultura está na música, longe da religião, mas não de qualquer religião. Esse mesmo estranhamento não aparece em relação à maior parte do patrimônio material brasileiro, composto por obras sacras, incluindo igrejas e imagens de devoção a santos. 
Ainda que essa declaração reconheça o gospel como música e, portanto, como cultura, com objeção apenas quanto à relação com o Estado, o status de "arte" (sem dúvida símbolo de distinção, mesmo no interior dos diferentes sentidos atribuídos ao conceito de "cultura" ${ }^{9}$ ) não é unanimemente reconhecido.

É possível perceber o estranhamento do próprio jornalista ao afirmar que o projeto dá status de "artista" aos profissionais do ramo (ou seja, que para ele não o tinham) e que “cantores, pastores, padres, parlamentares evangélicos e católicos que entoam esses cânticos e hinos de louvor cristãos poderão ser contratados como artistas [grifo meu] e ter direito aos benefícios de isenção fiscal da Lei Rouanet".

Se e a equação entre cultura e religião já não era unânime, a relação entre ambas e a política soa suspeitíssima. É com esse tom que a Folha de São Paulo tratou a questão. A matéria era ilustrada por uma emblemática foto da cantora Aline Barros em tons claros, olhando para cima (para os céus?), sorridente, com os cabelos longos ao vento e com o que parecem ser raios ao fundo. Uma imagem que destoava nos tons e na diagramação proposta para aquele exemplar do jornal e remetia a uma iconografia religiosa, ironicamente, próxima às representações de Santa Maria.

A ênfase dessa matéria é num caráter desnecessário da emenda, relatando que alguns eventos de música gospel já haviam sido contemplados pela Lei Rouanet e contando com o endosso de Henilton Parente, então secretário de fomento e incentivo à cultura como "especialista convidado" a dar declaração de autoridade: "É uma coisa de reafirmação. O gospel já é reconhecido como cultura apenas por ser música".

O interessante é que esse argumento de redundância se combina com citação do parecer de Bebeto Alves, que sugeria cautela com a medida e deixa a dúvida: se a emenda é redundante, por que "cautela"?

O Bispo Rodovalho, autor do projeto, foi chamado a falar no encerramento um tanto irônico da matéria:

Rodovalho disse não ter expectativa de aumento de patrocínio para eventos gospel, por "preconceito" das empresas.

\footnotetext{
${ }^{9}$ Como demonstra Raymond Williams (2007), uma das formas do conceito de Cultura mais bem sucedidas nos processos de colonização foi a que o associa à "arte", como categoria distintiva.
} 
Fundador da igreja Sara Nossa Terra, ele é autor de livros e CDs religiosos. Nega, contudo, ter apresentado a proposta em causa própria. "Minha produção é muito pequena para isso. Eu não sou dos melhores de voz, mas sou amado", diz o bispo que faz parte do grupo proprietário da editora e gravadora Sara Brasil.

Ou seja, temos aqui outro "incômodo" para essa equação: o interesse econômico. Como empresário do ramo gospel, Rodovalho teria interesses particulares na emenda que propõe enquanto parlamentar. Se as críticas comuns à Lei Rouanet apontam para um favorecimento de interesses privados, a presença da religião traz um efeito ainda mais incômodo a essa conexão, que sai da discussão dos "interesses econômicos" e os condensa na figura do parlamentar-pastor-cantor-empresário.

Lembramos, assim, que Economia, Política e Religião são imaginadas como esferas diversas, reinos próprios cuja combinação demanda muitas mediações para não parecerem ilegítimas. Essa configuração, no entanto, pode ser considerada espúria por razões diferentes. Ou melhor, o lugar de onde se fala pode determinar diferentes elementos contaminadores. Para o parecer do MinC, como vimos, o elemento contaminador parece ser a relação com a religiosidade.

A nota oficial, publicada no site do MinC, era breve e falava em um "gênero evangélico" de música. A resposta ao comentário de um leitor demonstra que o representante da comunicação não se responsabiliza pela constitucionalidade da emenda:

Andre 21 de dezembro de 2011

É constitucional uma lei deste tipo? E o princípio que o Estado é laico?

RESPOSTA: André, não se trata de uma lei de inciativa do poder Executivo. Foi proposta, discutida e votada no âmbito do Congresso Nacional; o controle de constitucionalidade das leis cabe ao poder Judiciário, quando provocado.

Embora os principais veículos evangélicos de comunicação tenham divulgado matérias otimistas, comemorando a medida, não é sem contradições que o vocabulário da 'cultura' se afirma para os evangélicos, o que, aliás, só começou a ocorrer muito recentemente e de maneira tópica (MAFRA, 2011).

O eixo de respeito universal às singularidades pressuposto por este discurso pode ser apropriado como avanço em relação a uma perseguição aos evangélicos. A página oficial de Magno Malta, senador pelo Partido da República e cantor gospel, demonstra com nitidez esse ponto de vista. A notícia comemora 
o reconhecimento oficial de um Estado Laico que acaba com o preconceito cultural contra melodia, harmonia e ritmo sublimes que inspiraram fortemente os principais estilos da canção popular (...) quebra de vez no Brasil o estigma contra o gospel, um gênero musical de conteúdo religioso que nasceu nos Estados Unidos no Século 20.

Assim, é afirmada a existência de um "estigma" e um "preconceito cultural" contra a música gospel. A aprovação da lei é vista por Magno Malta como "um gesto de lealdade e justiça da Presidenta da República” que "reconheceu que a música gospel tem se disseminado no Brasil e isso significa que grande parcela da sociedade é admiradora do estilo musical.”

A lei viria

tratar o artista gospel com o mesmo respeito que são tratados os músicos sertanejos, clássicos, populares e outros estilos mais jovens. Música, com mensagens positivas, são remédios para alma, independente da crença. Estou feliz com a publicação da nova lei, uma clara demonstração de que estamos vencendo a intolerância, o preconceito e a discriminação de alguns setores sectários

Temos, portanto, a linha de argumentação comum a muitas medidas afirmativas de "minorias", com a alegação de "preconceito", "intolerância" e "discriminação" que seriam reparados por um reconhecimento oficial que recolocaria a especificidade do gênero no interior de uma universalidade atestada por um Estado laico. O gospel passa de gênero específico de uma religião à raiz de um importante tronco da música mundial ${ }^{10}$ e um "remédio pra alma, independente da crença".

Esse tipo de adesão à linha mais comum de argumentação da "arma da cultura" (MAFRA, 2011) não é comum entre os evangélicos brasileiros e também não é consensual. Há, também, quem enxergue a inserção em um espectro universal como um eixo de perigo, que pressupõe equanimidade entre as singularidades e pode significar a aceitação e a valorização de outras 'minorias'. Cito dois exemplos tomados dos campos de "comentários" a essas notícias otimistas, que, pela liberdade que o espaço "semianônimo" da internet permite, demonstram isso com muita clareza.

\footnotetext{
${ }^{10}$ A matéria segue dizendo que "O gospel influenciou fortemente os principais estilos da canção popular norteamericana, como o rhythm'n'blues, o rock'n'roll e a soul music. Além de interpretações de Elvis Presley, Ray Charles e Sam Cooke, a canção gospel destacou-se também nas vozes de Aretha Franklin e Mahalia Jackson. Já a música erudita brasileira nasceu nas igrejas, com o barroco mineiro e baiano. Prosseguiu como banda sinfônica e música de salão no século 19. Seu grande compositor do período, Carlos Gomes, foi em verdade um dos elos da evolução da ópera na Itália. Leopoldo Miguez tinha fortes vínculos com a estética wagneriana.O nacionalismo só se esboça com Alberto Nepomuceno e ganha força com Heitor Villa-Lobos, o mais representativo do modernismo."
} 
No portal "Verdade Gospel", principal veículo virtual de notícias da Assembleia de Deus Vitória em Cristo, do famoso pastor Silas Malafaia, a notícia da sanção à emenda recebeu, entre outros, dois emblemáticos comentários:

\author{
rique jose disse: \\ 11 de janeiro de 2012 às 13:52 \\ TOMARA QUE ELES NAO USEM ESSA LEI PRA QUANDO FOR VOTADA A \\ PL122, EX: FOI APROVADA UME [sic] LEI PRA ELES O [sic] GAYS TBM \\ TEM DIREITO...... TEMOS QUE TOMAR CUIDADO........ [...] \\ silas lopes de campos disse: \\ 11 de janeiro de 2012 às 18:40 \\ Preste muita atenção nesse trecho da notícia: "No entanto, para receber os benefícios \\ da lei, os eventos não podem ser promovidos pelas igrejas."... \\ DEUS nos diz, através da Bíblia, que devemos ser diferentes das pessoas que \\ caminham para a perdição. Essa lei não passa de uma maneira disfaçada [sic] de \\ misturar os cristãos aos mundanos...por trás dessa faxada [sic] há um plano \\ diabólico da união anticristo
}

A mistura entre as esferas também pode ser problemática do ponto de vista das empresas. O que os produtores gospel relatam é que as marcas teriam restrições a se associarem aos seus eventos. Por essa razão, o reconhecimento simbólico de manifestação cultural teria ainda mais importância para neutralizar o aspecto visto como negativo da religião, atribuindo uma especificidade que carrega o valor de 'diversidade' cultural. A questão aparece na coluna de música do portal UOL (Universo Online) no dia 10/01/2012:

\begin{abstract}
Para o diretor da gravadora gospel "Canzion", Daniel Nunes, a lei pode incentivar o aumento de shows gospel, porque o gênero "está na moda". No entanto, o fato de a música religiosa no país ainda estar muito ligada à religião -- diferente do que ocorre nos Estados Unidos, que é mais considerada como um gênero musical-- ainda pode afastar patrocinadores particulares: "As marcas não querem se associar a essas bandas. A cultura de considerar música gospel como gênero musical vai demorar muito para mudar no Brasil. Não acho que a lei vá mudar isso, mas pode ajudar", diz.
\end{abstract}

Assim, a aproximação com a universalidade e laicidade do Estado também teria o efeito de alargar o espectro de alcance econômico do gospel. A referência ao mercado estadunidense como exemplo do que é desejado demonstra que há a intenção de dar aos valores, conteúdos e formas evangélicos o mesmo tom de universalidade que eles possuem em um país de maioria e tradição protestante, onde os valores dos grupos evangélicos podem passar ao debate como se fossem valores de toda a sociedade. Algo que tem paralelo com a enorme influência católica no Brasil, como demonstrou Emerson Giumbelli (2002). 
Para atrair mais patrocínios é preciso que o específico dialogue com o universal, para que não se restrinjam nichos de consumidores, alguns dos quais podem ver o campo religioso com maus olhos. Ou seja, a religião também não é bem-vinda incondicionalmente no reino da economia.

A “área cinza” entre economia, política e religião demanda um vocabulário próprio para se tornar inteligível e legitimada. Esse vocabulário tem sido muitas vezes o da 'cultura'. O fato de que esse recurso não tem sido utilizado tradicionalmente pelos evangélicos torna esse caso interessante para iluminar os limites e as manobras desse discurso.

É preciso perguntar, a esta altura, por que o debate da cultura se tornou uma alternativa para os evangélicos?

\section{3-A arma e o genérico}

A noção de "diversidade cultural" (conceito antropológico e suas diferentes apropriações bem mais recentes), tal como ocorreu com o conceito de secularização, também transpõe fronteiras acadêmicas e "espirala pela sociedade”(...). Este "efeito teoria" - usando agora uma expressão cunhada por Pierre Bourdieu - também não é sem consequências para o que acontece no interior e, também, no exterior do mundo acadêmico. ${ }^{11}$

Regina Novaes

Como vimos, a Lei ${ }^{\circ}$ 12.590/2012 apenas reafirma uma possibilidade que já estava prevista do ponto de vista legal. Projetos gospel já haviam sido contemplados pela Lei Rouanet. A música gospel é o segundo gênero mais vendido no país e esse mercado está consolidado e movimenta bilhões. Parlamentares evangélicos vêm sendo eleitos e atuando no legislativo inclusive por meio de uma frente parlamentar que reúne representantes de diversos partidos. Por que razão então o esforço em torno desta emenda? Por que utilizar o discurso da cultura?

Esta pergunta é o lado avesso do problema colocado por Clara Mafra (2011). A questão proposta por ela é por que, até então, o discurso da cultura (a "arma da cultura", como ela chama, inspirada em Marshall Sahlins) não tem sido utilizado largamente pelos

11 NOVAES, Regina. Juventude, religião e espaço público: exemplos “bons pra pensar” tempos e sinais. Religião e Sociedade, Rio de Janeiro, n.32, v. 1, p.184-208, 2012. P. 190. 
evangélicos. Sua pergunta parte de outro polo: da grande presença de elementos religiosos no que se reconheceu como patrimônio brasileiro.

O patrimônio material nacional seria majoritariamente de igrejas e objetos de arte sacra católicos, refletindo a inserção ancestral desta Igreja na narrativa nacional. (GIUMBELLI, 2008). Já o "povo do candomblé” teria tido sucesso na utilização dessa arma como estratégia de defesa e reconhecimento de suas práticas como patrimônio imaterial e, sendo parte da história e da identidade nacional, reivindicar direitos e uma história reconhecida (BIRMAN, 2006).

Para a autora, a dificuldade dos evangélicos para acionar o mesmo recurso se daria por características internas a esse grupo. Mais do que um caráter iconoclasta (já que ao longo do texto são demonstradas algumas maneiras de forjar objetos de memória mesmo sob esse paradigma), o que estaria em questão seria uma memória interna, resiliente a diálogos com a narrativa nacional. Uma "cultura parcial”, já que Mafra parte de uma ideia de pluralidade entre os evangélicos (analisa três estratégias acionadas por três denominações).

O caso que analisamos aqui é diferente. Não diz respeito a conciliar uma denominação específica com o discurso nacional. Não se trata de uma medida da Igreja Sara Nossa Terra, do Bispo Rodovalho. Nem sequer de uma proposta apenas de evangélicos, como já chamamos a atenção ${ }^{12}$. Trata-se de um espectro genérico, um grupo de evangélicos em geral. Uma frente. Um mercado.

O evangélico genérico não é apenas uma constatação do censo, é também elemento que se leva em conta nos cálculos políticos. É também um projeto. É uma ideia de que há uma 'cultura' evangélica compartilhada. A “arma da cultura” não é utilizada para a conquista de direitos negados. Seu uso (assim como, a criação da Frente Parlamentar Evangélica) enfatiza um referencial genérico de evangélico. E o esforço aqui é precisamente para obter o reconhecimento de um "Estado laico", como comemora Magno Malta. Mais do que obter recursos, a emenda permite inserir-se no discurso da nação e na Lei do Estado.

\footnotetext{
12 A participação católica fica em segundo plano pelo estranhamento que causa a relação evangélica com a narrativa nacional. Também porque o termo gospel tem uma acepção geral mais relacionada aos evangélicos (apesar de seus artistas de maior sucesso serem católicos). Avalio assim, as consequências simbólicas da emenda como abatendo-se prioritariamente sobre os evangélicos. Embora a medida seja beneficiadora também das músicas católicas e a emenda tenha sido apoiada pela frente parlamentar católica a maior parte da crítica, como vimos, se dirige aos evangélicos.
} 
A aproximação da universalidade do Estado laico confere legitimidade para além dos identificados com alguma religião. O discurso da "cautela" sugerida pelo MinC, ou do questionamento acerca da constitucionalidade acionam exatamente a mesma ideia legitimadora: o Estado. É ele o garantidor do "universal" que, nesse caso, correria perigo de tomada pela religião. A “catequese".

O Estado é, portanto, central no argumento de ambos os lados. O aferidor de legitimidade. Como é possível que ambos os lados utilizem essa "arma"? Por que um grupo como os evangélicos, que já ocupa um espaço relevante em termos de adeptos e de movimentação financeira, opta por inserir-se também no discurso do Estado? Para compreender isso é preciso problematizar o cerne do argumento: a ideia de Estado. E, sim, isso mesmo, tratar o Estado como ideia, em alguma medida.

Essa não é uma proposta nova. É bem antiga, aliás. Um de seus desenvolvimentos mais frutíferos está no desafio que Philip Abrams colocou em um artigo sob o singelo título de "notas sobre a dificuldade de estudar o Estado" e que, na verdade, punha de ponta-cabeça toda a teoria utilizada para tratar do Estado na longínqua década de 1970.

A proposta deste autor é abandonar o Estado como conceito explicativo. Para ele, o Estado não é um agente ou um lugar de disputa. O Estado é performado. É uma ideia e também um sistema de práticas, que lhe dá realidade, mas que não tem realidade para além dessas práticas. Um discurso capaz de legitimar relações de poder que de outra forma seriam ilegítimas. Capaz de deslocar a atenção das práticas e agentes concretos de poder e as reunir sob esse agente impessoal, nessa esfera isolada, que se pretende diversa da "economia" e da "religião".

O uso do Estado como conceito explicativo teria como consequência a reiteração do aspecto legitimador dessa ideia. Abrams critica as principais maneiras de investigar o Estado, a sociologia política e o marxismo, que por diferentes razões teriam conferido autoridade à ideia de Estado, seja por focar em processos de decisão e "segredos de Estado", seja por, no caso do marxismo, tentar conciliar uma noção de que o Estado é ideologia com uma prática política que propõe uma disputa do Estado.

Por isso mesmo, trabalhar com o conceito de Estado para além de sua história e de sua operação como forma de legitimação do poder, seria corroborar essa própria legitimação. E a 
melhor maneira de lidar com isso seria justamente resgatar a história da sua construção. A história da ideia de Estado e das práticas do "estado-sistema" identificado com ela.

É esse caráter legitimador que é afetado na percepção dos opositores da emenda. O Estado em questão não pode ser legítimo, se invadido pela religião. Se a ideia de Estado capaz de atribuir legitimidade à crítica da emenda do gospel é fundada na ideia de laicidade, a história desse conceito, por outro lado, demonstra que a integração de elementos religiosos é constitutiva do desenvolvimento da ideia de Estado.

É o que demonstra Talal Asad (2003), ao identificar que as dificuldades do desenvolvimento de políticas públicas na Europa que contemplem grupos muçulmanos, assim como a atribuição da pecha de fundamentalistas a muitos desses grupos, têm relação com a forma como o ocidente viu serem forjadas as ideias de "Estado", "religião" e "laicidade". A "religião" que foi separada da política nas lutas por essa nova configuração de poder tinha como tipo ideal a Igreja Católica, como forma concorrente de centralização de poder.

Asad recorre para o entendimento desse discurso a um entrecruzamento ainda mais profundo, revelado por Michel Foucault (2008). Foucault estabelece uma genealogia das artes de governar em que é possível perceber importantes continuidades entre o governo de populações e o pastorado cristão, no qual a obediência era um fim em si mesmo e o papel do pastor estava em garantir a seu rebanho a sobrevivência.

Desta formulação derivam dois aspectos importantes para os objetivos deste trabalho: a relativização do caráter laico das configurações de poder que se cristalizaram na ideia de Estado, citada acima, e a importância do desenvolvimento de certos saberes como tecnologias de poder para a crescente importância que o "governo" como forma de poder adquire. Os textos de Foucault apontam para a estatística e a medicina como dois desses grandes saberes. Há quem sugira, porém, que a atual fronteira do "governo" é primordialmente a "política cultural" e que um de seus saberes estruturantes é a antropologia (MILLER E YÚDICE, 2002).

Embora fosse necessário um enorme esforço de pesquisa (ainda não realizado) para confirmar essa hipótese, esse insight tem a vantagem de iluminar com clareza a relação entre a antropologia como saber e a legitimação e construção de novas formas de poder que procuram englobar antigas resistências sob o paradigma da diversidade cultural. 
Se a utilização de Estado como conceito explicativo por parte das ciências sociais cumpriu papel importante na construção de sua legitimação (MITCHELL, 1999; ABRAMS, 1977), esse também é um elemento que confere legitimidade à "cultura". A “cultura" como "conceito antropológico" passou a inspirar as conferências e documentos de organismos internacionais, como a UNESCO, que contou com a autoridade e assinatura de diversos antropólogos reconhecidos (WRIGHT, 1999; MILLER E YÚDICE, 2002)

Creio que é preciso, por isso ter com a 'cultura' o mesmo cuidado sugerido por Abrams (1977) para a análise do Estado. A diversidade cultural como valor, como objetivo em si mesma, não é capaz de resolver os conflitos, embora tenha efeitos apaziguadores. Ela é também um discurso legitimador, uma arma que pode ser acionada pelos diferentes sujeitos em disputa. Isso não depende, portanto, da complexidade do conceito de 'cultura' utilizado ou de uma adequação de sua formulação.

Susan Wright (1999) chama a atenção para essa questão demonstrando que a direita inglesa utilizou uma versão recente e complexa do conceito de 'cultura' para implementar políticas racistas. A hostilidade em relação a imigrantes era apresentada como uma defesa legítima da própria identidade e os esforços de promoção de igualdade de direitos das "minorias" como um ataque racista ao direito à diversidade desses grupos. Já o 'velho' conceito de 'cultura' (que leva a história e as diferenças internas pouco em conta) teria sido mobilizado com sucesso pelos Kayapós, para ganhar visibilidade e reivindicar seu direito à coexistência na sociedade dominante.

No Brasil, desde a redemocratização, a "arma da cultura" vinha sendo utilizada com sucesso por diversos grupos marginalizados na luta por expansão de direitos e pela conquista de legitimidade e respeito social. É o caso do Funk, reconhecido como patrimônio do Rio de Janeiro após uma série de ações que contaram com participação direta de antropólogos na redação do projeto.

É também o caso de religiões afro-brasileiras, um dos grupos mais enfatizados nas pregações de algumas denominações evangélicas, em que são identificados com o diabo e o inimigo a ser combatido em uma batalha espiritual (BIRMAN, 2012). Historicamente objeto de preconceito e repressão, a articulação nacional do "povo do candomblé" construiu uma brecha para sua versão da história na narrativa nacional. 
Após as últimas duas décadas de inserção dos evangélicos como força política na vida parlamentar, a ênfase em pautas morais e a forma como os embates se deram na mídia construíram uma imagem da atuação evangélica como contrária ao paradigma da diversidade.

Gera surpresa, portanto, como vimos, a utilização por este grupo de um vocabulário, identificado pelo uso na defesa de grupos como homossexuais e religiões afro-brasileiras, que se construíram midiaticamente como os grandes inimigos dos evangélicos. Por essa razão a ponderação feita no comentário de um leitor do site "Verdade Gospel" demonstra estranhamento quanto ao uso por parte dos evangélicos dos mesmos argumentos de outras "minorias".

A questão nesse caso não é pela conquista de direitos historicamente negados, mas de um grupo que deseja conferir universalidade a seus valores. Esse vocabulário é capaz de unir a esfera religiosa e a estatal sem que se afete a legitimidade conferida por elas, sem as desnaturalizar.

A justificativa do projeto aciona justamente elementos de minoria. A história da escravidão (pilar para o reconhecimento dos cultos afro-brasileiros) é importada dos Estados Unidos e uma dificuldade de aprovação dos projetos alegada como índice de preconceito. Por outro lado, o argumento da cultura, desvinculado do culto religioso e das igrejas, aponta para um novo modo de ser evangélico: o evangélico genérico.

Esse pertencimento, que não é dado apenas por uma prática de cultos e vinculação institucional, é parte de um processo maior, em que uma geração de jovens vivenciou um mundo no qual o catolicismo já não era uma identificação automática com a nação e a existência de diversas igrejas evangélicas já era um fato corriqueiro (NOVAES, 2012).

O discurso da 'cultura', portanto, utilizado para a legitimação do gospel, não é apenas uma tentativa de ampliação de recursos para esse mercado ou uma luta por conquista de direitos negados. É a construção de um espaço reconhecido na narrativa nacional, de uma imagem genérica de evangélico, capaz de reunir em uma identidade 'cultural' referências para experiências múltiplas e que não podem ser acionadas pela vinculação institucional. Um espaço de produção de significados capaz de permear as "esferas".

Lembrando ainda uma vez o desafio proposto por Abrams (1977) acerca do Estado e o alerta de Regina Novaes (2012) para a necessidade de desnaturalizar os conceitos propostos 
pelas ciências sociais, é importante que a capacidade de apaziguamento e obliteração de conflitos do vocabulário da 'cultura' seja colocada em cheque. É preciso iluminar os limites dessa "arma" e de sua legitimidade quando ela é acionada na prática.

O caso da Lei $n^{\circ}$ 12.590/2012 demonstra algumas dessas questões que talvez sejam menos perceptíveis nos usos de grupos já tradicionalmente identificados com a 'cultura'. Os significados mobilizados por críticos e defensores mostram que, quando acionada na prática, essa arma encontra limites à sua legitimidade e capacidade de articulação entre universal e específico.

\section{Referências Bibliográficas:}

ABRAMS, Philip. Notes on the difficulty of studying the state. Journal of Historical Sociology, n.1 v.1, p. 58-89, 1988 (1997).

ASAD, T. Formations of the secular. Christianity, Islam, Modernity. Stanford: Standford UP, 2003. Genealogies of Religion: Discipline and Reasons of Power in Christianity and Islam. Baltimore: The Johns Hopkins University Press, 1993.

BENNETT, Andy. Subcultures or Neo-Tribes? Rethinking the Relationship between Youth, Style and Musical Taste. Sociology , p. 33: 599, 1999.

BIRMAN, Patricia. Percursos afro e conexões sociais: negritude, pentecostalismo e espiritualidades. In: Faustino Teixeira e Renata Menezes (Orgs.). As religiões no Brasil. Continuidades e Rupturas. Petrópolis: Vozes, 2006. O poder da fé, o milagre do poder: mediadores evangélicos e deslocamentos de fronteiras sociais. Horizontes Antropológicos, Porto Alegre, ano 18, n. 37, p. 133-153, jan./jun. 2012.

FOUCAULT, Michel. Segurança, Território e População. São Paulo: Martins Fontes, 2008.

GARCÍA CANCLINI, Néstor. Políticas Culturales em America Latina. Mexico D.F.: Editorial Grijalbo, 1987.

GIUMBELLI, E. O fim da religião. Dilemas da liberdade religiosa no Brasil e na França. São Paulo: Attar/PRONEX, 2002. A presença do religioso no espaço público: modalidades no Brasil. Religião e Sociedade, v. 28, n. 2, 2008.

MAFRA, Clara. A"arma da cultura" e os "universalismos parciais". Mana, Rio de Janeiro, v. 17, n. 3, Dec. 2011 .

MILLER, Toby e YÚDICE, George. Cultural Policy. London: Sage publications, 2002.

MITCHELL, T. Society, Economy, and the State Effect. In: STEINMETS, G. (Org.) State/Culture: State-Formation after the Cultural Turn. Ithaca: Cornell University, 1999. 
NOVAES, Regina. Juventude, religião e espaço público: exemplos "bons pra pensar" tempos e sinais. Religião e Sociedade, Rio de Janeiro, n.32, v. 1, p.184-208, 2012.

OLIVIERI, Cristiane Garcia. Cultura neoliberal: leis de incentivo como política pública de cultura. Escrituras, São Paulo: Instituto Pensarte, 2004.

RUBIM, Antonio Albino Canelas e BARBALHO, Alexandre. Políticas Culturais no Brasil. Salvador: EDUFBA, 2007.

SAHLINS, Marshall. O 'pessimismo sentimental' e a experiência etnográfica: por que a cultura não é um 'objeto' em via de extinção (Partes I e II). Mana. Estudos de Antropologia Social, n.3 v.1, p.41-74; n.3, v.2, p.103-150, 1997.

SARKOVAS, Yacoff. O incentivo fiscal no Brasil. Revista Teoria e Debate. São Paulo, n. 62, p. 58-62, abr./maio, 2005.

WILLIAMS, Raymond. Palavras-chaves. Um vocabulário de Cultura e Sociedade. São Paulo: Boitempo, 2007.

WRIGHT, Susan. The politicization of 'Culture', Anthropology Today, v. 14, n.1, p.7-15, 1999.

\title{
THE GOSPEL MUSIC AND THE USES OF "CULTURE". REFLEXIONS ON A LAW PROJECT.
}

\begin{abstract}
This article's about the recognition of gospel music as a cultural movement in Brazil. Although the Law of Incentive for Culture (Rouanet Law - number 8313/91) already recognized music as a field able to draw investments and some gospel projects already been awarded with funds, the amendment received criticism and even a negative opinion from the Ministry of Culture itself. The analysis of this debate allows us to discuss the different meanings behind key terms such as "culture", "state" and "religion". This analysis echoes the work of authors such as Talal Asad and Susan Wright, who have shown that these key terms should be understood as historically constructed and as "native" categories capable of justifying and denying certain configurations of power. Thus, the debate on the use of "culture" by evangelicals in Brazil (for which Clara Mafra drew attention in 2011) reveals strong connections between religion and the implementation of public policies in the country.
\end{abstract}

KEY-WORDS: Cultural Policy - Gospel music - Evangelicals - Policy - Religion 